Supplement of Wind Energ. Sci., 1, 221-236, 2016

http://www.wind-energ-sci.net/1/221/2016/

doi:10.5194/wes-1-221-2016-supplement

(C) Author(s) 2016. CC Attribution 3.0 License.

(c) (i)

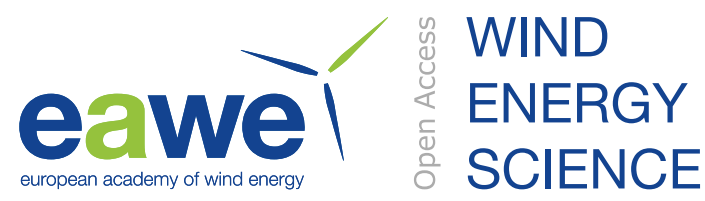

Supplement of

\title{
Wind turbine power production and annual energy production depend on atmospheric stability and turbulence
}

Clara M. St. Martin et al.

Correspondence to: Clara M. St. Martin (clara.st.martin@colorado.edu)

The copyright of individual parts of the supplement might differ from the CC-BY 3.0 licence. 


\section{Supplement}

\section{S1 Lidar variability}

Lidar measurements of wind speed and direction exhibit larger variability than those from the met tower. This variability may be due to the lidar's operating assumption of homogeneity across the measurement volume: the WINDCUBE v1 measures volumetric-averaged wind speeds and directions over a $20 \mathrm{~m}$ thick layer with an effective diameter on the order of the height of the measurement $\left(30^{\circ}\right.$ beam angle) and assumes homogeneous flow within that layer. This assumption may not be reliable at this site: observations from scanning lidar of flow at the U.S. Department of Energy (DOE) National Wind Technology Center (NWTC) at the National Renewable Energy Laboratory (NREL) indicate that flow can be very inhomogeneous (Smalikho et al., 2013; Aitken et al., 2014).

Despite this potential for variability at the NWTC, the lidar and tower measurements are generally wellcorrelated $\left(\mathrm{R}=0.96\right.$ and bias of $0.37 \mathrm{~m} \mathrm{~s}^{-1}$, with the lidar recording higher values than the anemometer for this time period; Fig. 8). Note that the bias is likely significantly influenced by the accuracies of the instrument compared (see Sect. 2.2.1 and Sect. 2.2.2). Previous work by Smith et al. (2006), Sathe et al. (2011) and Sanz Rodrigo et al. (2013) saw strong correlations between lidars and anemometers in flat terrain. Smith et al. (2006) found a correlation coefficient of 0.9843 between a ZephIR lidar and a cup anemometer at $80 \mathrm{~m}$ for 10 -min wind speed averages for 1 day, Sathe et al. (2011) found correlation coefficients greater than 0.98 between WINDCUBE and ZephIR lidars and sonic anemometers at $100 \mathrm{~m}$ for 10-min wind speed averages for 4-5 months, and Sanz Rodrigo et al. (2013) found correlation coefficients greater than 0.99 between WINDCUBE and ZephIR lidars and cup anemometers at $89 \mathrm{~m}$ for 10-min wind speed averages for 10 days. Sanz Rodrigo et al. (2013) also performed lidar-tower comparisons in complex terrain in the Alaiz mountain range in Navarra, Spain, and found correlation coefficients greater than 0.98 between WINDCUBE and ZephIR lidars and cup anemometers at $78 \mathrm{~m}$ for 10-min wind speed averages for approximately 5 months. Our correlations between a lidar and an anemometer, based on 2.5 months of collecting wind speed and direction-filtered data in complex terrain in an atmosphere with relatively few aerosols for backscatter, resulted in a relatively high correlation coefficient of 0.96 . Our correlation in an inhomogeneous flow is only slightly lower than other correlation coefficients previously found between lidars and towers in flat terrain.

\section{S2 Rotor equivalent wind speed}


Quantifying the wind profile across the entire swept rotor area (SRA) has been shown to improve correlations between wind inflow and power output (Wagner et al., 2009). Here, we calculate rotor equivalent wind speeds (REWS) following Wagner et al. (2009):

$U_{e q}=\left(\sum_{i} U_{i}{ }^{3} \frac{A_{i}}{A_{\text {tot }}}\right)^{1 / 3}$,

where i represents the index of the level, $U$ is the horizontal wind speed, $A_{i}$ is the area of the turbine rotor disk of the level with the corresponding data point (the area of the sector defined by chord/arc relative to $360^{\circ}$, minus the area of the triangle), and $A_{\text {tot }}$ is the SRA. When calculating the REWS from the lidar profiles, five levels $(40,60,80,100$, $120 \mathrm{~m})$ are available; when calculating the REWS from the tower cup anemometer data, three levels $(55,80,105 \mathrm{~m})$ are available, all of which use Thies anemometers. Cup anemometer data available at 38, 87, and $122 \mathrm{~m}$ are not used in these REWS calculations for consistency because these are different instruments than those at 55, 80, and $105 \mathrm{~m}$, which were are to calculate the REWS.

Despite the variability in the shear exponent as calculated from the tower measurements (Sect. 3.7), the high correlations between the 80-m wind speeds and REWS shown in Fig. S1 suggest that power curves for $80 \mathrm{~m}$ will be very similar to power curves for REWS for this data set. The high turbulence at the NWTC may have prevented the occurrence of larger wind shear across the rotor disk. This might lead to significant differences in REWS from 80-m wind speeds, which may manifest in the power curves at other sites. Differences between the REWS and the wind speed at hub height at other sites may also affect annual energy production calculations as in Scheurich et al. (2016).

\section{S3 Yaw error and veer}

Additionally, we explore the effects of yaw error and wind veer and distributions of these variables as shown in Fig. S2. To calculate yaw error, we subtract the wind direction as measured by the met tower near hub-height from the nacelle position as given by the supervisory control and data acquisition (SCADA) system. The resulting yaw error, however, is centered around $90^{\circ}$ instead of $0^{\circ}$, which means the orientation of the turbine position is around $90^{\circ}$ off of North. To correct for this, we assume that the yaw error should be $0^{\circ}$ at rated power, so we take the average yaw error when the turbine was producing rated power $\left(94.22^{\circ}\right)$ and subtract this from the yaw error to get the correct values of yaw error. After correcting for the turbine yaw orientation offset, we determined that it is not appropriate 
to split the yaw error distribution into regimes as $78 \%$ of the data lie within $\pm 5^{\circ}$ yaw error and $96 \%$ of the data lie within $\pm 10^{\circ}$ yaw error.

We found no impact of yaw error or wind veer on the power curves at this site. However, based on other locations (Vanderwende and Lundquist, 2012; Rhodes and Lundquist, 2013; Walton et al., 2014) where significant veer does occur, it may affect power production, but this site does not regularly experience that phenomena.

\section{S4 Power curves for different TKE regimes}

Likely due to a lack of sonic data at $74 \mathrm{~m}$ that passes our data quality control filters as discussed in Sect. 3.1 (60 \%), few statistically-distinct bins emerge from the TKE power curves. Fig. S3 shows the nacelle and upwind tower power curves segregated by TKE regime. Only at about $12 \mathrm{~m} \mathrm{~s}^{-1}$ do statistically-significant differences in power curves emerge between the low and high TKE power curves: at $12 \mathrm{~m} \mathrm{~s}^{-1}$, cases within the low TKE regime produce significantly more power than cases within the high TKE regime.

\section{References}

Aitken, M.L., Lundquist, J.K., Pichugina, Y.L., and Banta, R.M.: Quantifying wind turbine wake characteristics from scanning remote sensor data, J. Atmos. Ocean. Tech. 31, 765-787, doi:10.1175/JTECH-D-13-00104.1, 2014.

Rhodes, M.E., and Lundquist, J.K.: The effect of wind turbine wakes on summertime US Midwest atmospheric wind profiles as observed with ground-based Doppler LIDAR, Boundary-Layer Meteorol., 149, 85-103, doi:10.1007/s10546-013-9834-x, 2013.

Sanz Rodrigo, J., Borbón Guillén, F., Gómez Arranz, P., Courtney, M.S., Wagner, R., and Dupont, E.: Multi-site testing and evaluation of remote sensing instruments for wind energy applications, Renewable Energy, 53, 200-210, 2013.

Sathe, A., Mann, J., Gottschall, J., and Courtney, M.S.: Can wind LIDARs measure turbulence?, J. Atmos. Ocean. Tech., 28, 857-868, doi:10.1175/JTECH-D-10-05004.1, 2011.

Scheurich F, Enevoldsen, P. B., Paulsen, H. N., Dickow, K. K., Fiedel, M., Loeven, A., and Antoniou, I.: Improving the accuracy of wind turbine power curve validation by the rotor equivalent wind speed concept, Journal of Physics: Conference Series, 753, 1-7, doi: 10.1088/1742-6596/753/7/072029,2016.

Smalikho, I.N., Banakh, V.A, Pichugina, Y.L., Brewer, W.A., Banta, R.M., Lundquist, J.K., and Kelley, N.D.: LIDAR investigation of atmosphere effect on a wind turbine wake, J. Atmos. Ocean. Tech., 30, $2554-2570,2013$.

Smith, D.A., Harris, M., Coffey, A., Mikkelsen, T., Jørgensen, H.E., and Mann, J.: Wind LIDAR evaluation at the Danish Wind Test Site in Høvsøre, Wind Energy, 9, 87-93, doi:10.1002/we.193, 2006.

Vanderwende, B., and Lundquist, J.K.: The modification of wind turbine performance by statistically distinct atmospheric regimes, Environ. Res. Lett., 7, 1-7, doi:10.1088/1748-9326/7/3/034035, 2012. 
Wagner, R., Antoniou, I., Pedersen, S., Courtney, M., and Jorgensen, H.: The influence of the wind speed profile on wind turbine performance measurements, Wind Energy, 12, 348-362, doi:10.1002/we.297, 2009.

Walton, R.A., Takle, E.S., and Gallus Jr., W.A.: Characteristics of 50-200-m winds and temperatures derived from an Iowa tall-tower network, J. Appl. Meteor. Clim., 53, 2387-2393, doi:10.1175/JAMC-D-13-0340.1, 2014.

\section{Supplementary Figures}
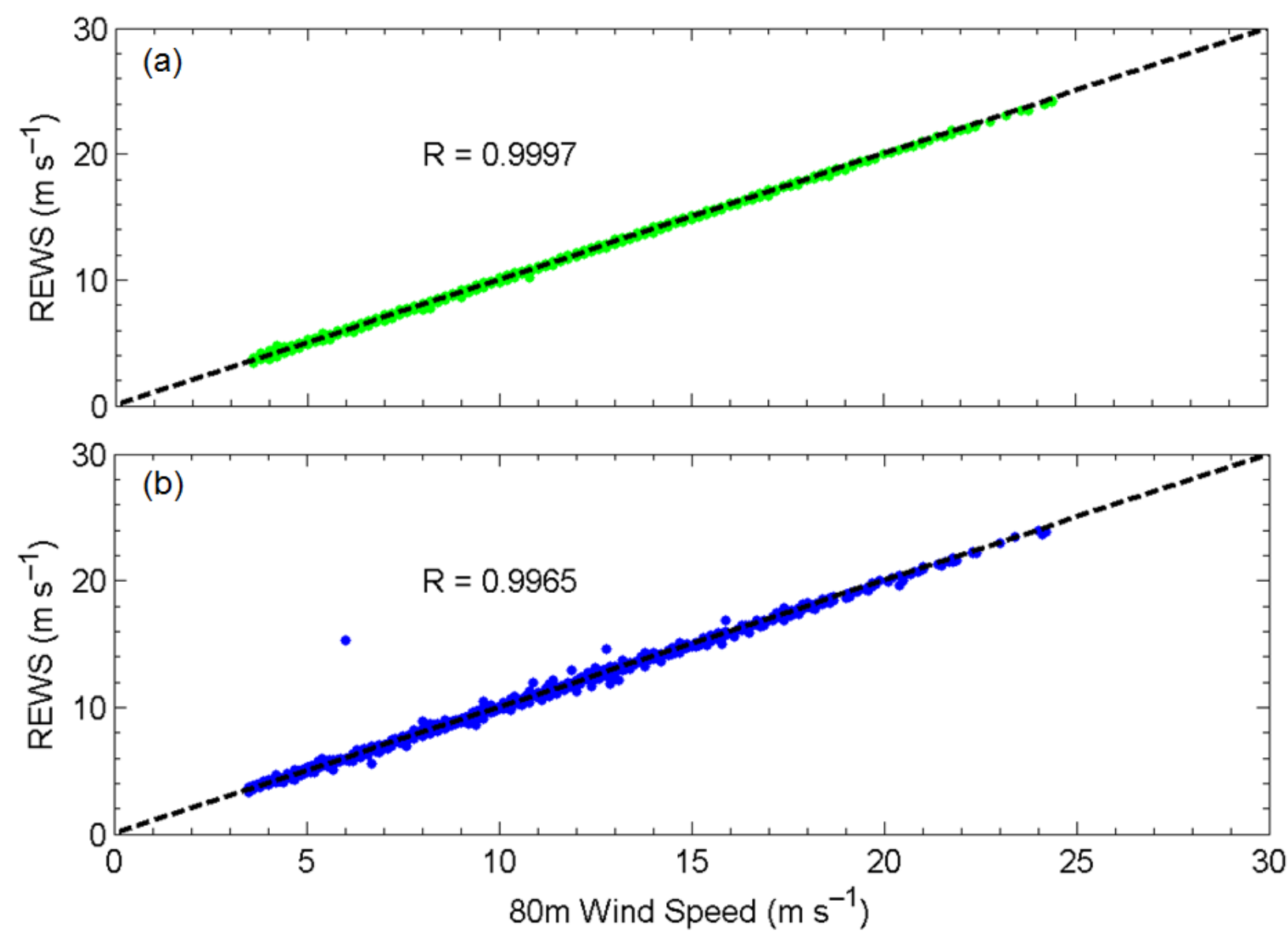

Figure S1. REWS as a function of 80-m wind speed from (a) the tower and from (b) lidar. Black dotted line represents a 1:1 relationship. Includes data filtered for tower $80-\mathrm{m}$ wind speeds between 3.5 and $25.0 \mathrm{~m} \mathrm{~s}^{-1}, 87-\mathrm{m}$ wind directions between $235^{\circ}$ and $315^{\circ}$, and for normal turbine operation. 

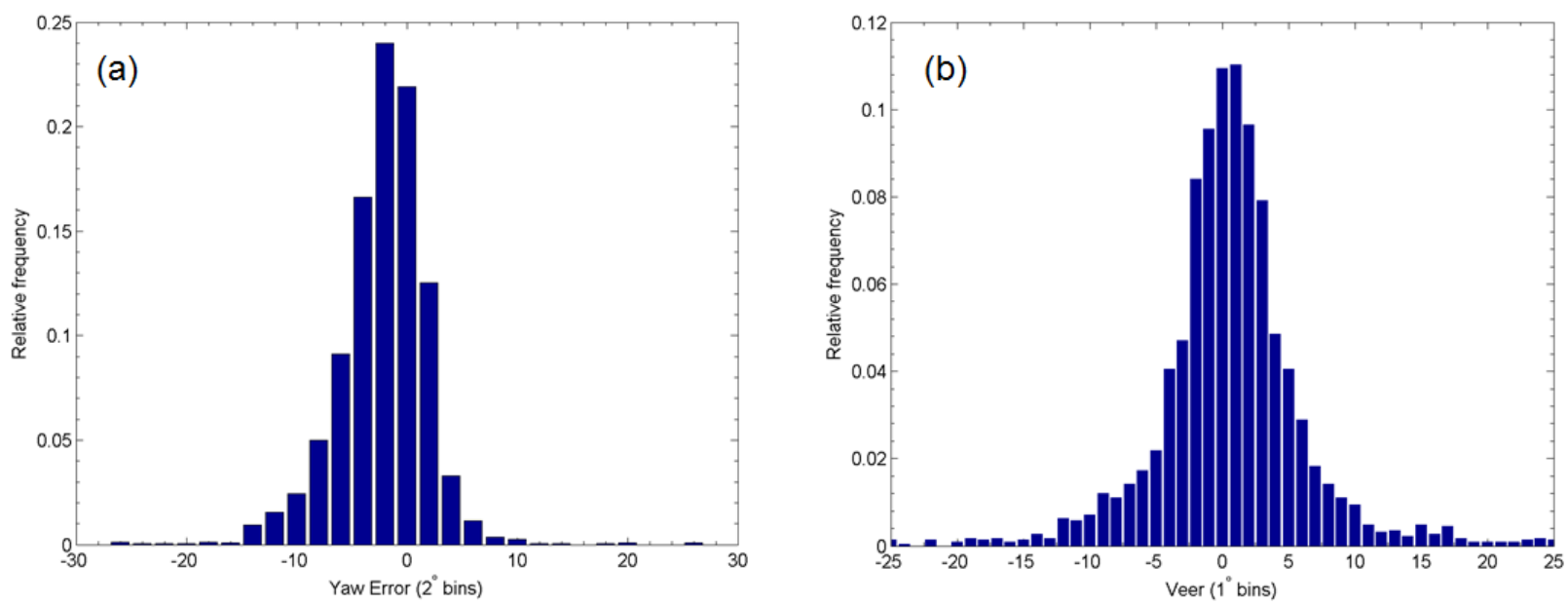

Figure S2. (a) Yaw error histogram and (b) wind veer histogram. Includes data filtered for tower 80-m wind speeds between 3.5 and $25.0 \mathrm{~m} \mathrm{~s}^{-1}, 87-\mathrm{m}$ wind directions between $235^{\circ}$ and $315^{\circ}$, and for normal turbine operation. 

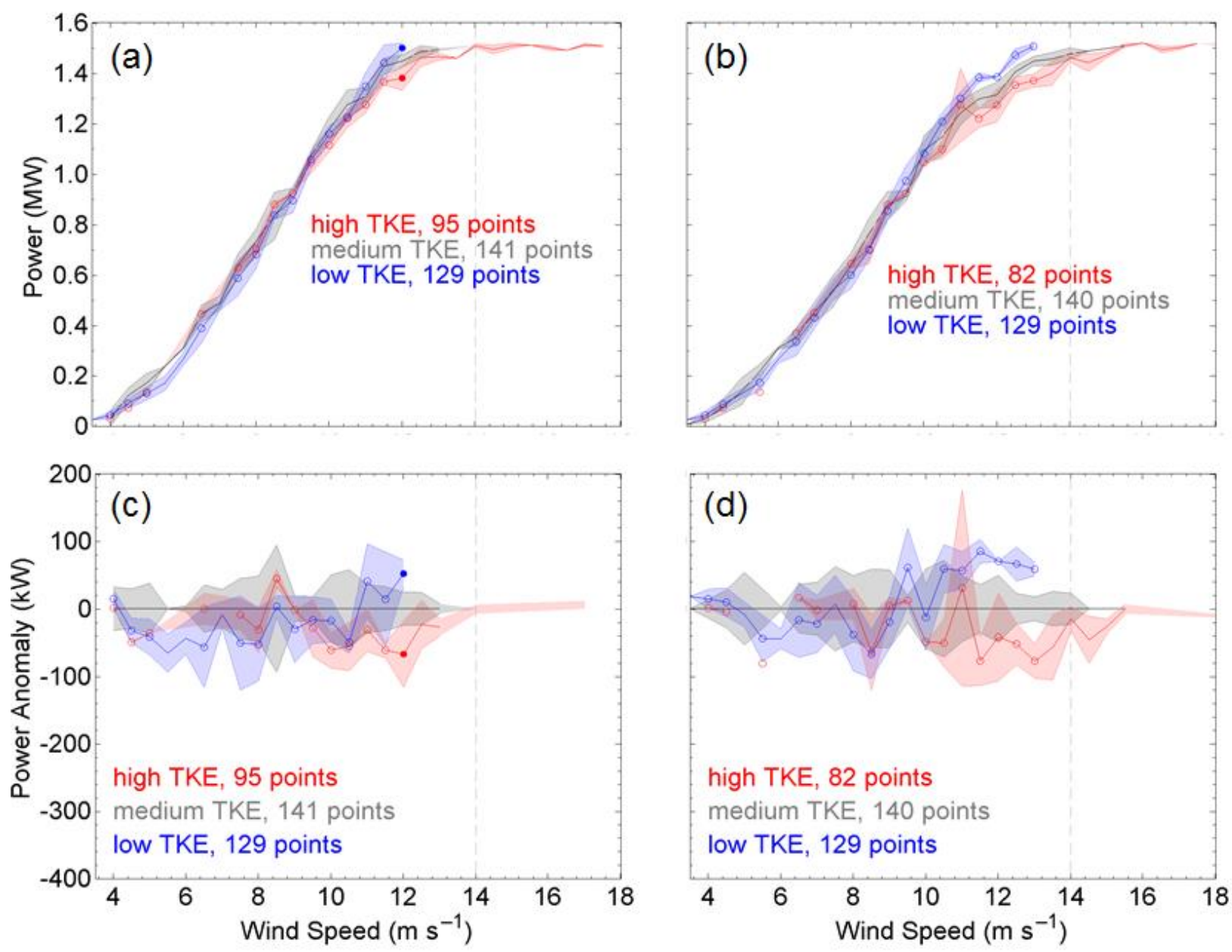

Figure S3. (a) Nacelle anemometer and (b) 80-m tower anemometer power curves with TKE regimes. (c) Naclle anemometer and (d) 80-m tower anemometer power curves shown as the anomaly from the neutral or medium power curve of the TI regimes. Median statistics are used to avoid outlier effects. Statistically distinct differences within each wind speed bin between the regimes are determined by the Wilcoxon rank sum test with a $1 \%$ significance level and denoted by closed circles. Includes data filtered for tower $80-\mathrm{m}$ wind speeds between 3.5 and $25.0 \mathrm{~m} \mathrm{~s}^{-1}, 87-\mathrm{m}$ wind directions between $235^{\circ}$ and $315^{\circ}$, and for normal turbine operation. Envelopes represent $\pm 1 \mathrm{MAD}$ for each wind speed bin. The grey dashed line marks rated speed. 